\title{
Effect of Family Presence on Pain and Anxiety Levels among Patients during Invasive Nursing Procedures in an Emergency Department
}

\section{Parvin Abdi Gheshlaghi}

Shaheed Beheshti University of Medical Sciences

\section{Ziba Barzabadi Farahani}

Shaheed Beheshti University of Medical Sciences

Sima Zohari Anboohi

Shaheed Beheshti University of Medical Sciences

\section{Malihe Nasiri}

Azarbaijan Shahid Madani University

Arash Ziapour ( $\nabla$ arashziapoor@gmail.com )

Kermanshah University of Medical Sciences https://orcid.org/0000-0001-8687-7484

Vahid Hatami Garosi

Kermanshah University of Medical Sciences

\section{Research}

Keywords: Family Presence, Pain, Anxiety, Invasive Nursing Procedure, Emergency Department

Posted Date: March 9th, 2020

DOI: https://doi.org/10.21203/rs.3.rs-16337/v1

License: (c) (i) This work is licensed under a Creative Commons Attribution 4.0 International License. Read Full License 


\section{Abstract}

Background: It is widely accepted that pain is the most common complaint during invasive nursing procedures, which causes anxiety in patients. The purpose of this study was to determine the effect of family presence on the level of pain and anxiety of patients during invasive nursing procedures in emergency department.

Methods: The present non-randomized controlled clinical trial was conducted on 70 patients referred to emergency department at selected hospital affiliated to Kermanshah University of Medical Sciences, Iran, in 2018, who were selected by convenience sampling method and then randomly assigned into two groups of intervention (even days) and control (odd days). The invasive nursing procedure was performed for the intervention group in the family presence for physical and psychological support and for the control group without the family presence. Data collection tools were the Spielberger State-Trait Anxiety Inventory (STAI) and the Visual Analogue Scale (VAS). SPSS version 23 software was used to compare the mean scores of pain and anxiety using independent t-test.

Results: The mean pain score after the invasive procedure had no significant difference between the intervention group $(3.9 \pm 1.5)$ and the control group (4.7 \pm 1.9$)(P=0.073)$. In the intervention group, the mean score of anxiety after invasive procedure was significantly lower than before the invasive procedure $(P=0.028)$, whereas the control group showed no change $(P=0.556)$.

Conclusion: The family presence during the invasive nursing procedures reduced the anxiety of patients but had no effect on their pain. Emergency nurses can take advantage of family presence during invasive procedures as a non-pharmacological intervention to reduce patients' anxiety.

\section{Background}

An invasive procedure is described as an action requiring the use of a device to enter the body through skin incision or puncture for diagnostic and therapeutic purposes [1]. Peripheral intravenous cannulation, intramuscular injection (IM), and venipuncture are some of the most repetitive invasive procedures in hospitals, often performed by nurses, which cause pain, anxiety, and discomfort in patients [2-4].

Pain is the most common complaint during invasive nursing procedures [5], which causes physical and mental stress and increases anxiety during treatment procedures if controlled improperly, causes stress and adverse physical consequences, and increases avoidance of therapeutic procedures, thereby distrusting the patient towards the nurse, while trust is a prerequisite for effective communication [6].

The pain from invasive procedures often causes anxiety and distress in the patient [7]. Almost all patients under medical care suffer from anxiety [8]. Most patients experience anxiety for a variety of reasons, including their illness and changes in the environment resulting from hospitalization. Exposure to painful processes exacerbates this anxiety [5]. The fear and anxiety experienced before a diagnostic and 
therapeutic intervention for many patients can have more significant negative effects than the intervention itself [9].

Pain relief and anxiety reduction are among the most basic human rights and should apply to all patients $[3,9]$. Nurses always use methods to reduce the pain and anxiety of patients before performing invasive procedures; for example, they encourage the patient to take a deep breath before injections and help to position them appropriately [10]. Pain and anxiety caused by invasive procedures can be moderated and controlled through a variety of approaches, including described pharmacological and nonpharmacological approaches; among which, independent or non-pharmacological approaches are considered to be desirable [8]. As a result, the nurses have been increasingly using these methods in recent years [6].

Distraction, massage, music therapy, therapeutic touch, acupuncture, acupressure, relaxation and breathing techniques and family presence are among the non-pharmacological ways to reduce pain and anxiety. The non-invasive nature, safety, absence of adverse effects and the ease of use are some of the advantages of these methods $[8,11,12]$. The family presence at bedside has recently been considered as a way to reduce pain and anxiety in patients $[5,13]$. The family presence is thought to reduce anxiety, especially during painful actions. It is believed that family presence reduces the pain experienced [5].

Saglik and Caglar (2019) stated that parental presence is effective in reducing pain in children during invasive procedures [14]. Naseri Salahshour et al. (2019) have shown that the presence of family members during endoscopy can decrease the level of patient's anxiety [15]. However, Islekdemir and Kaya (2016) came to contradictory results and stated that the family presence had no effect on the level of pain and anxiety of patients during invasive procedures [5].

The presence of relatives next to the patient is a recognized need and this need is felt real, especially at all painful moments [16]. In fact, the family members are the most important support persons for their loved ones, especially at sensitive times, such as when the patient is undergoing invasive procedures [17]. The patients often prefer to have their family members present during medical and nursing procedures [18]. Evidence suggests that most families also tend to be present on their patients during invasive procedures [19].

The family presence in the emergency department is a reality around the world. However, the family presence in some situations, such as emergency ones, is a challenging issue, especially for nurses. Although numerous international organizations have supported family presence during invasive procedures, the debate is still ongoing [20] and still some emergency departments are routinely barred from family presence that causes numerous damages to patients and their families [21]. The treatment team, including the nurses, decides on the family presence and practically encourages families to leave their patients during invasive procedures [22].

There is limited and contradictory information about the impact of family presence on pain and anxiety during invasive nursing procedures, especially for adult patients. On the other hand, the nurses make 
decisions about family presence during invasive procedures. Therefore, the current study aimed to investigate the effect of family presence on pain and anxiety of patients during invasive nursing procedures in the emergency department.

\section{Methods}

\section{Study design}

The present non-randomized controlled clinical trial was conducted in the emergency department at selected hospital affiliated to Kermanshah University of Medical Sciences, Iran. The research units included newly admitted Level-3 patients (based on the Emergency Severity Index (ESI) triage), who met the inclusion criteria. Sample size was calculated 32 for each group using previous studies (5) based on the equation of (type I error: 1.96, type II error: 0.85 , test power: 0.80 , and observed effect size: 0.70 ). Considering the $10 \%$ dropout, the final sample size was considered to be 35 patients. Therefore, 70 patients were selected by convenience sampling method and assigned into intervention and control groups.

Because the presence of a caregiver for a number of patients may cause discontent to patients without a caregiver that is ethically incorrect, there was no possibility of random assignment. The intervention group members were selected in even days and control group members in odd days. It was impossible to meet the two groups each other according to the determination of the status of the patients within less than six hours (discharge, hospitalization, referral or dispatch to another center), which is important indicator of emergency department.

Inclusion criteria were the age of 18 to 65 years, consciousness, communication and cooperation, being subjected to invasive nursing procedures while admission in the emergency room, presence of a caregiver, no anxiety and psychological disorders, no history of diabetes, no use of hypnotics and tranquilizers, no addictive and psychotropic drugs, no severe pain, and no taking sedatives on admission. Exclusion criteria included any complication during the intervention (failure of invasive nursing procedure or the alteration of patient triage to lower level) and unwillingness to continue to participate in the study.

Data were collected using demographic and clinical information questionnaire, Spielberger State-Trait Anxiety Inventory (STAI) and Visual Analogue Scale (VAS). The demographic and clinical information questionnaire consisted of age, gender, marital status, living status, educational level, employment status, type of invasive nursing procedure and history of doing this procedure and family member relationship with the patient (in the intervention group). Content validity was used to determine the validity of the demographic and clinical information questionnaire. Thus, the relevant form was prepared after studying the relevant references, and corrected with the comments of ten faculty members of the Nursing and Midwifery School at Shahid Beheshti University.

The STAl is a standardized and commonly used questionnaire developed by Spielberger et al. in 1970 with two parts of state and trait anxiety. The state anxiety scale measures a person's feelings at the time 
of answering (5), including 20 items, each rated on a 4-point Likert scale. The total score ranged from 20 to 80 and higher scores indicated higher anxiety. The trait anxiety indicates mild (the score of 21-40), moderate (the score of 41-60) and severe (the score of 61-80) anxiety. In a study of Najafi et al. (2014), the reliability coefficient of this tool with Cronbach's alpha was 0.89 . Its concurrent validity has been confirmed by clinical interviews and a number of anxiety assessment tools [23]. In this study, the reliability was determined using Cronbach's alpha test which was 0.90 , indicating high and acceptable range. The VAS is the most widely used (one-dimensional) tool for measuring pain around the world [24]) using a straight 10-cm line representing the words "no pain" at the left-most end and "worst pain imaginable" at the right-most end. The patients mark this line according to the extent of their pain, and then a numerical representation of their pain severity is determined by measuring the distance between the left-most end and the point where the patients have marked [25]. This tool has been widely used in national and international studies and its validity and reliability have been demonstrated [12].

After obtaining the necessary permits and coordinating, the researcher went to the selected hospital affiliated to Kermanshah University of Medical Sciences, introduced himself to the research units, provided sufficient explanations to them and obtained informed written consent if they wish to participate in the study. At first, the demographic and clinical information questionnaires were completed for all the research units on admission, and then the STAI questionnaire was filled in for both intervention and control groups. Next, in the intervention group, an invasive nursing procedure recorded in the emergency record, including peripheral intravenous cannulation, intramuscular injection and venipuncture, was performed by the nurse in the presence of a family member. The family member (spouse, father, mother, child, sister, brother, or person who had a kinship or emotional relationship with the patient) was selected with the patients' willingness to attend the emergency room monitored by them until hospitalization. The caregiver-patient relationship was recorded in a demographic and clinical information questionnaire. Necessary explanations were given to the caregiver in the intervention group before the study, who was asked to encourage the patient during the invasive procedure and to provide physical and psychological support. In addition, compliance with the requirements such as non-intervention in the process of invasive procedure was taught. After rubbing alcohol, NOKAST pink peripheral venous catheter [20] was used for venipuncture and a 3-cc syringe with $23 \mathrm{G}$ needle (Avapezeshk Company) was applied for intramuscular injection and blood sampling.

In the control group, the invasive nursing procedure recorded in the patient's file was performed without family presence. In fact, family members of the control group were encouraged to leave their patients in different ways, such as explaining the aims of the study. Immediately after the end of the invasive nursing procedure, the pain intensity was measured by VAS and the STAl questionnaire was re-completed in two groups. It should be noted that all medication and treatment were tailored to the patient's condition based on the routine emergency department for both groups. It was impossible to adjust to ambient conditions that affect the patient's level of anxiety (such as light and sound) due to the nature of the emergency department, and it was impossible to blind to the nature of the research.

\section{Data analysis}


Descriptive statistics including mean, standard deviation, range, frequency and percentage and inferential statistics were used for data analysis. Paired t-test was used for intragroup comparison of the mean pain and anxiety scores, and independent t-test for intergroup comparison. Significance level was considered to be $P<0.05$. All analyzes were performed by SPSS 23 software.

\section{Ethical Considerations}

Ethical approval was obtained from the Ethical Review Committee of SBMU. The purpose of the study was explained to all participants. Writteninformed consent was obtained from all participants. and they were assured of anonymity and confidentiality.

\section{Results}

In this study, 70 patients were selected by convenience sampling method and then randomly assigned into intervention and control groups of 35 . The results showed that $54.3 \%$ of the participants were female and $45.7 \%$ were male. The mean age of participants was $38.60 \pm 10.49$ years. The minimum age of patients was 26 years and the maximum was 65 years. Most patients in both groups were married and lived with their families. Almost half of the patients in both groups had an academic educational level, and $34.3 \%$ of the intervention group was laborer and $34.4 \%$ of the control group was housekeepers. The caregiver in $28.6 \%$ of the patients in the intervention group was their spouse. In terms of type of invasive nursing procedure, most patients $(74.3 \%)$ in both groups experienced venipuncture and almost all participants $(91.4 \%)$ had a history of invasive procedure. Background variables were evaluated and compared using the independent t-test, Mann-Whitney and Fisher's exact tests in the intervention and control groups; the two groups had no statistically significant difference and were homogeneous $(\mathrm{P}<$ 0.05) (Tables 1 and 2).

According to Table 3, the mean pain score after invasive procedures was $3.9 \pm 1.5$ in the intervention group and $4.7 \pm 1.9$ in the control group, and the independent t-test showed no significant difference $(P=$ 0.073).

The mean anxiety score of patients before the invasive procedures in the intervention group was significantly lower than the control group $(P=0.001)$ (Table 4). Consequently, the analysis of covariance test was used to compare the mean anxiety score after the invasive procedure in the two groups. Results showed that the mean anxiety score after the invasive procedures in the intervention group was significantly lower than in the control group $(P<0.05)($ Table 5$)$. The mean anxiety score was significantly decreased after the invasive procedure in the intervention group when comparing with prior to the invasive procedure $(P=0.028)$, while it did not change in the control group $(P=0.555)$ (Table 6). Most of the patients had mild anxiety in the intervention group and moderate anxiety in the control group before and after the invasive procedures (Table 7). 
Table 1

Descriptive and inferential statistics based on age in patients referred to emergency department at selected hospital affiliated to Kermanshah University of Medical Sciences, Iran, in 2018 between intervention and control groups

\begin{tabular}{|llllll|}
\hline Age (year) & Mean \pm SD & Number & Minimum & Maximum & Independent t-test \\
\hline Intervention & $37.31 \pm 10.01$ & 35 & 27 & 62 & $\mathrm{t}=1.025$ \\
Control & $39.89 \pm 10.95$ & 35 & 26 & 65 & $\mathrm{p}=0.309$ \\
\cline { 1 - 4 } Total & $38.60 \pm 10.49$ & 70 & 26 & 65 & \\
\hline
\end{tabular}


Table 2

Descriptive and inferential statistics based on underlying variables in patients referred to emergency department at selected hospital affiliated to Kermanshah University of Medical Sciences, Iran, in 2018 between intervention and control groups

\begin{tabular}{|c|c|c|c|c|c|c|}
\hline \multirow[t]{2}{*}{ Variables } & \multirow[t]{2}{*}{ subgroups } & \multicolumn{2}{|l|}{ Intervention } & \multicolumn{2}{|l|}{ Control } & \multirow{2}{*}{$\begin{array}{l}\text { Statistica } \\
\text { test } \\
\text { results }\end{array}$} \\
\hline & & Frequency & Percentage & Frequency & Percentage & \\
\hline Gender & $\begin{array}{l}\text { Female } \\
\text { Male }\end{array}$ & $\begin{array}{l}19 \\
16\end{array}$ & $\begin{array}{l}54.3 \\
45.7\end{array}$ & $\begin{array}{l}19 \\
16\end{array}$ & $\begin{array}{l}54.3 \\
45.7\end{array}$ & \\
\hline $\begin{array}{l}\text { Marital } \\
\text { status }\end{array}$ & $\begin{array}{l}\text { Single } \\
\text { Married } \\
\text { Deceased } \\
\text { spouse } \\
\text { Divorced }\end{array}$ & $\begin{array}{l}9 \\
22 \\
2 \\
2\end{array}$ & $\begin{array}{l}25.7 \\
62.9 \\
5.7 \\
5.7\end{array}$ & $\begin{array}{l}8 \\
26 \\
0 \\
1\end{array}$ & $\begin{array}{l}22.9 \\
74.3 \\
0.0 \\
2.9\end{array}$ & $\begin{array}{l}\text { Exact } \\
=2.7 \\
p=0.436\end{array}$ \\
\hline Living status & $\begin{array}{l}\text { Alone } \\
\text { With spouse } \\
\text { With family }\end{array}$ & $\begin{array}{l}1 \\
9 \\
25\end{array}$ & $\begin{array}{l}2.92 \\
5.7 \\
71.4\end{array}$ & $\begin{array}{l}2 \\
10 \\
23\end{array}$ & $\begin{array}{l}5.7 \\
28.6 \\
65.7\end{array}$ & $\begin{array}{l}\text { Exact } \\
=0.4 \\
p=0.791\end{array}$ \\
\hline $\begin{array}{l}\text { Educational } \\
\text { level }\end{array}$ & $\begin{array}{l}\text { Primary } \\
\text { school } \\
\text { Secondary } \\
\text { school } \\
\text { High school } \\
\text { Academic }\end{array}$ & $\begin{array}{l}1 \\
6 \\
12 \\
16\end{array}$ & $\begin{array}{l}2.9 \\
17.1 \\
34.3 \\
45.7\end{array}$ & $\begin{array}{l}2 \\
1 \\
13 \\
19\end{array}$ & $\begin{array}{l}5.7 \\
2.9 \\
37.1 \\
54.3\end{array}$ & $\begin{array}{l}Z^{* *}= \\
0.961 \\
p=0.336\end{array}$ \\
\hline $\begin{array}{l}\text { Employment } \\
\text { status }\end{array}$ & $\begin{array}{l}\text { Unemployed } \\
\text { Housekeeper } \\
\text { Self-employed } \\
\text { Laborer } \\
\text { Retiree } \\
\text { Employee }\end{array}$ & $\begin{array}{l}5 \\
9 \\
2 \\
12 \\
0 \\
7\end{array}$ & $\begin{array}{l}14.3 \\
25.7 \\
5.7 \\
34.3 \\
0.0 \\
20.0\end{array}$ & $\begin{array}{l}2 \\
12 \\
2 \\
10 \\
2 \\
7\end{array}$ & $\begin{array}{l}5.7 \\
34.3 \\
5.7 \\
28.6 \\
5.7 \\
20.0\end{array}$ & $\begin{array}{l}\text { Exact } \\
=3.8 \\
p=0.564\end{array}$ \\
\hline Caregiver & $\begin{array}{l}\text { Parents } \\
\text { Spouse } \\
\text { Child } \\
\text { Siblings } \\
\text { Relatives } \\
\text { Friends }\end{array}$ & $\begin{array}{l}10 \\
10 \\
2 \\
5 \\
4 \\
4\end{array}$ & $\begin{array}{l}28.6 \\
28.6 \\
5.7 \\
14.3 \\
11.4 \\
11.4\end{array}$ & - & - & - \\
\hline $\begin{array}{l}\text { Type of } \\
\text { invasive } \\
\text { nursing } \\
\text { procedure }\end{array}$ & $\begin{array}{l}\text { Peripheral } \\
\text { intravenous } \\
\text { cannulation } \\
\text { intramuscular } \\
\text { injection } \\
\text { venipuncture }\end{array}$ & $\begin{array}{l}26 \\
6 \\
3\end{array}$ & $\begin{array}{l}74.3 \\
17.1 \\
8.6\end{array}$ & $\begin{array}{l}26 \\
5 \\
4\end{array}$ & $\begin{array}{l}74.3 \\
14.3 \\
11.4\end{array}$ & $\begin{array}{l}\text { Exact } \\
=0.2 \\
p=0.890\end{array}$ \\
\hline $\begin{array}{l}\text { History of } \\
\text { invasive } \\
\text { nursing } \\
\text { procedure }\end{array}$ & $\begin{array}{l}\text { Yes } \\
\text { No }\end{array}$ & $\begin{array}{l}32 \\
3\end{array}$ & $\begin{array}{l}91.4 \\
8.6\end{array}$ & $\begin{array}{l}32 \\
3\end{array}$ & $\begin{array}{l}91.4 \\
8.6\end{array}$ & - \\
\hline
\end{tabular}


Table 3

Descriptive and inferential statistics based on pain score after invasive procedure in patients referred to emergency department at selected hospital

affiliated to Kermanshah University of Medical Sciences, Iran, in 2018 between intervention and control groups

\begin{tabular}{|lllll|}
\hline Pain score & Mean \pm SD & Minimum & Maximum & Independent $\mathrm{t}$-test \\
\hline Intervention & $3.9 \pm 1.5$ & 1 & 7 & $\mathrm{t}=1.8$ \\
Control & $4.7 \pm 1.9$ & 1 & 9 & $\mathrm{p}=0.073$ \\
\cline { 1 - 4 } Total & $4.3 \pm 1.8$ & 1 & 9 & \\
\hline
\end{tabular}

Table 4

Descriptive and inferential statistics based on anxiety score before invasive procedure in patients referred to emergency department at selected hospital affiliated to Kermanshah University of Medical Sciences, Iran, in 2018 between intervention and control groups

\begin{tabular}{|llll|}
\hline Anxiety score & Intervention & Control & Independent $t$-test \\
\cline { 2 - 3 } & Mean \pm SD & Mean \pm SD & $t=3.611$ \\
Before invasive procedure & $39.25 \pm 9.74$ & $48.57 \pm 11.74$ & \\
\hline
\end{tabular}

Table 5

Analysis of covariance model results

\begin{tabular}{|lllll|}
\hline Anxiety score & $\boldsymbol{\beta}$ coefficient & standard error & t-value & $\boldsymbol{p}$-value \\
\hline Before invasive procedure & 0.91 & 0.07 & 12.68 & 0.000 \\
\hline Intervention group & -3.73 & 1.6 & -2.23 & 0.029 \\
\hline Control group & - & - & - & - \\
\hline
\end{tabular}


Table 6

Descriptive and inferential statistics based on anxiety score

before and after invasive procedure in patients referred to emergency department at selected hospital affiliated to

Kermanshah University of Medical Sciences, Iran, in 2018

between intervention and control groups

\begin{tabular}{|lll|}
\hline Anxiety score & Intervention & Control \\
\cline { 2 - 3 } & Mean \pm SD & Mean \pm SD \\
\hline Before invasive procedure & $39.25 \pm 9.74$ & $48.57 \pm 11.74$ \\
\hline After invasive procedure & $36.00 \pm 10.47$ & $48.22 \pm 12.82$ \\
\hline Paired t-test & $\mathrm{t}=2.289$ & $\mathrm{t}=0.594$ \\
& $\mathrm{p}=0.028$ & $\mathrm{p}=0.556$ \\
\hline
\end{tabular}

Table 7

Frequency distribution of anxiety intensity before and after invasive procedure in patients referred to emergency department at selected hospital affiliated to Kermanshah University of Medical Sciences, Iran, in 2018 between intervention and control groups

\begin{tabular}{|c|c|c|c|c|c|}
\hline \multirow[t]{2}{*}{ Anxiety intensity } & & \multicolumn{2}{|c|}{ Intervention } & \multicolumn{2}{|l|}{ Control } \\
\hline & & Frequency & Percentage & Frequency & Percentage \\
\hline \multirow[t]{3}{*}{ Before invasive procedure } & Mild & 24 & 68.57 & 10 & 28.57 \\
\hline & Moderate & 10 & 28.57 & 19 & 54.28 \\
\hline & Severe & 1 & 2.85 & 6 & 17.14 \\
\hline \multirow[t]{3}{*}{ After invasive procedure } & Mild & 19 & 54.28 & 12 & 34.28 \\
\hline & Moderate & 15 & 42.28 & 20 & 57.14 \\
\hline & Severe & 1 & 2.86 & 3 & 8.57 \\
\hline
\end{tabular}

\section{Discussion}

The purpose of this study was to investigate the effect of family presence on the level of pain and anxiety of patients during invasive nursing procedures in emergency department. The results showed that there was no statistically significant difference in the mean pain score after invasive nursing procedures in both intervention and control groups $(P=0.073)$ and thus the family presence had no effect on the pain level. 
Islekdemir and Kaya (2016) stated that the family presence during invasive nursing procedures had no effect on patients' pain level. The mean scores of pain due to invasive procedures in the intervention and control groups were similar to the present study and this is justified by the similarity of the pain assessment scale and the types of invasive procedures performed in the two studies [5]. Tantikul and Theeranate (2014) showed that the presence of trained parents did not affect children's pain tolerance during common invasive procedures (venipuncture and blood sampling) [26]. Ozcetin et al. (2011) reported that parental presence had little positive effect on children's pain level during blood sampling [27]. Rafiee Vardanjani et al. (2012) reported that the presence of a trained caregiver could not reduce the pain level in women during childbirth [28]. Similarly, Motarjemi Zadeh et al. (2017) showed that the parental presence during induction of anesthesia did not affect the pediatric postoperative pain [29]. Overall, it can be stated that the presence of a caregiver, even if it is selected by the patient's desire and has received the necessary training for physical and psychological support, often has no effect on the level of pain, whether in children or adults, and this conclusion is justified by the physiology of pain. In this study, the short duration of support and environmental factors related to emergency department, such as noise, partly justify the lack of family presence influence on the pain.

However, there are also inconsistent results in this regard. Al-Abbass et al. (2016) concluded that the parental presence significantly reduced the pain level in children during venipuncture [13]. This can be explained by differences in the study sample (children versus adults). Children are more dependent on their family members, which may reduce their pain experience in the presence of their parents. On the other hand, the family presence through distraction reduces pain perception [30]. Numerous studies have demonstrated the positive effect of different distraction methods on reducing pain in children during invasive procedures [17, 31].

Before $(P=0.001)$ and after $(P<0.05)$ invasive procedures, the mean anxiety score in the intervention group was significantly lower than in the control group. In the intervention group, the mean anxiety score after the invasive procedure was significantly lower when comparing with prior to the invasive procedure $(P=0.028)$, but there was no significant difference in the control group $(P=0.556)$. As a result, the family presence led to a significant decrease in the anxiety level in the patients.

Some patients experienced severe anxiety (the score over 60 on the STAI questionnaire), indicating the need for nurses to pay attention to anxiety during invasive procedures. Similarly, in the delivery sector, Rafiee Vardanjani et al. (2012), Sameei Zadeh Toosi et al. (2010) and Salehi et al. (2016) reported that the presence of a trained caregiver significantly reduced the level of maternal anxiety during delivery [28, 32, 33]. In addition, Salehi et al. showed that the closer the caregiver's relationship with the patient, the greater the impact of the caregiver's presence on reducing patient anxiety. The results of a study by Kherad et al. (2016) in burn intensive care units showed that regular family attendance reduced the anxiety level in the burn patients [34]. Koohi et al. (2017) reported that the family participation in primary care provision reduced the level of anxiety from burn pain [35]. In the cardiac intensive care unit, Bashti et al. (2016) showed that scheduled family visits affect the anxiety level in the patients with angina [18]. Motarjemi Zadeh et al. (2017) examined the effect of parental presence during induction of anesthesia 
on pediatric emergency agitation after strabismus surgery and found that children in the intervention group had significantly more sedation scores than in the control group [29]. In general, it can be concluded that the presence of a caregiver, especially if selected by the patient's desire and trained for physical and psychological support, in particular if it is in the form of regular attendance and scheduled visits during hospitalization, can reduce patients' anxiety level, as social support is one of the effective factors in controlling anxiety, and the role of family members is one of the key components in social support $[16,35]$. The family members can help patients reduce anxiety and provide support for them [34], and family presence during invasive nursing procedures reduces the patients' anxiety level [5].

However, there are also inconsistent studies in this area. Rasti Emad Abadi et al. (2014) showed that parental presence had no significant beneficial effect on the anxiety level of children undergoing surgery. In this study, although the mean postoperative anxiety score was significantly lower in the intervention group than in the control group, as in the present study, but there were no significant differences between the two intervention and control groups before and after the surgery [9]. Surgery is one of the most frightening treatments for children, and perhaps the severity of anxiety can diminish the impact of family presence. Islekdemir and Kaya (2016) stated that the family presence during invasive nursing procedures did not affect patients' anxiety [5]. Although this study was similar to the present study in many respects, contradictory results were obtained. It may be possible to justify the paradox that the research units of the present study included the patients of level 3 "newly admitted" to the emergency department, and that the family presence, especially in the first few hours of hospitalization, may be able to calm the patient. On the other hand, this can be justified by differences in patient culture.

\section{Conclusion}

The invasive nursing procedures, especially in busy sections of the hospital, such as the emergency department, are so common that their complications (pain and anxiety) are forgotten. Adjustment and control of pain and anxiety caused by invasive procedures are central interventions and cause a lack of imposing additional suffering to patients. Emergency nurses can use family presence during invasive procedures as a safe, cost-effective and non-pharmacological intervention to reduce patients' anxiety and help educate family members about their calming role without causing problems during invasive procedures.

\section{Abbreviations}

FP:Family Presence; PAL:Pain and Anxiety Levels; PD:Patients during; IPNI:Invasive Nursing Procedures in an Emergency

\section{Declarations}

\section{Acknowledgments}

All participants in this study are appreciated. 


\section{Authors'contributions}

All authors were responsible for study. PAG was responsible for the study Conceptualization and led the writing of the paper. SFI conducted the Literature review and assisted in writing the paper. AZ conducted the Statistical analysis, assisted in interpreting the data and writing the paper. ZBF and SZA assisted with interpretation of the results and drafting programmatic Implications. $\mathrm{MN}, \mathrm{AZ}$ and VHG was responsible for data collection and coordination of the Study. AZ co-led the conceptualization, supervised all aspects of writing the Paper, and provided extensive comments on the manuscript. All the authors have read and approved the final manuscript.

\section{Funding}

There was no source of funding.

\section{Availability of data and materials}

Authors report that the data supporting their findings can be publicly shared.

\section{Ethics approval and consent to participate}

This study was drawn from a research project (No. IR. SBMU. PHNM. 1396.964) sponsored by the Deputy of Research and Technology at SBUMS.

\section{Consent for publication}

Not applicable.

\section{Competing interests}

The authors declare that they have no competing interests.

\section{Author details}

${ }^{1}$ Master of Emergency Nursing, Student Research Committee, School of Nursing and Midwifery, Shahid Beheshti University of Medical Sciences, Tehran, Iran. ${ }^{2}$ Assistant Professor, Department of MedicalSurgical Nursing, School of Nursing and Midwifery, Shahid Beheshti University of Medical Sciences, Tehran, Iran. ${ }^{3}$ Assistant Professor, Department of Medical-Surgical Nursing, School of Nursing and Midwifery, Shahid Beheshti University of Medical Sciences, Tehran, Iran. ${ }^{4}$ Assistant Professor, Department of Statistics, School of Nursing and Midwifery, Shahid Beheshti University of Medical Sciences, Tehran, Iran. ${ }^{5} \mathrm{PhD}$ Student of Health Education and Health Promotion, Health Institute, Kermanshah University of Medical Sciences, Kermanshah, Iran. ${ }^{6}$ MSc of Nursing, Kermanshah University of Medical Sciences. Kermanshah, Iran.

\section{References}


1. Ditzel A. Parent Presence During Invasive Procedures: The Implementation of a Clinical Practice Guideline and Educational Initiative. 2016.

2. Tee FY, Low C, Matizha P. Patient perceptions and experience of pain, anxiety and comfort during peripheral intravenous cannulation in medical wards: topical anaesthesia, effective communication, and empowerment. Int J Nurs Sci 2015;5(2):41-6. doi:10.5923/j.nursing.20150502.01.

3. Zore G, Dias R. Effectiveness of nursing interventions on pain associated with intramuscular injection. Int J Sci Res. 2014;3:1995-2000.

4. Rezaei K, Zand S, Baghcheghi N. Comparison of Biochemistry Values Obtained by Venipuncture and Saline Lock after Intermittent Administration of Fluids and drugs. J Arak Univ Med Sci. 2009;12(1):49-56.

5. İşlekdemir B, Kaya N. Effect of family presence on pain and anxiety during invasive nursing procedures in an emergency department: A randomized controlled experimental study. Int Emerg Nurs. 2016;24:39-45. doi: 10.1016/j.ienj.2015.05.008.

6. Razaghi N, Givari A, Tatarpoor P, Hoseini A. Comparing the effect of two methods of distraction and touch on intensity of pain related to venipuncture in 5-10 years old children. Iran J Nurs. 2012;25(77):50-9.

7. Khalili Shomia S, Safavi M, Yahyavi SH, Farahani H. Assessment of the effect of EMLA cream on vein puncture pain severity with vein catheter in the patients undergoing cesarean section: Randomized placebo controlled trial. J Mazandaran Univ Med Sci. 2012;22(91):82-8.

8. Nazem Zadeh N, Bagherian S, Miri S, Pashandi S, Shahriari M. Non-pharmaceutical methods of anxiety and pain control in children. J Res Commit Stud Sabzevar Univ Med Sci. 2013;17(1):31-9.

9. Rasti $R$, Jahanpour F, Motamed $N$. The effect of parental presence on anxiety during anesthesia induction in children 2 to 11 years of age undergoing surgery. J Jahrom Univ Med Sci. 2014;12(1):917.

10. NikbakhtNasrabadi A, Bakhshayeshi O, Parsayekta Z, Hoseyni M, Taghavi T, Rezvani H. The effectiveness of implementing nursing consultation on the anxiety of patients undergoing $\mathrm{GI}$ endoscopy. Iran J Nurs. 2012;25(79):54-62.

11. Modanloo M, Sayed Fatemi N, Bastani F, Peyrovi H, Behnampour N, Hesam M. Comparison of pain assessment by patients and triage nurses. Iran J Crit Care Nurs. 2010;4(1):23-8.

12. Lalegani $H$, Esmaili $S$, Safdari $A$. The effects of breathing techniques on pain intensity of burn dressing-A clinical randomized trial. J Clin Nurs Mid. 2013;2(4):61-8.

13. Al-Abbass $T$, Abdelkader $R$, Shoqirat $N$, Obeidat $H$. The effect of parental presence in decreasing pain level for children during venipuncture. Pyrex J Nurs Mid. 2016;2(3):12-9.

14. Sağlık DS, Çağlar S. The Effect of Parental Presence on Pain and Anxiety Levels During Invasive Procedures in the Pediatric Emergency Department. J Emerg Nurs. 2019;45(3):278-85. https://doi.org/10.1016/j.jen.2018.07.003.

15. Naseri-Salahshour V, Taher M, Karimy M, Abedi A, Fayazi N, Sajadi M, et al. The effect of presence of family members on the anxiety level of candidates for esophagogastroduodenoscopy: A randomized 
controlled trial. Med J Islamic Republic Iran. 2019;33:62-7. doi: 10.34171/mjiri.33.62.

16. Saglik DS, Caglar S. The Effect of Parental Presence on Pain and Anxiety Levels During Invasive Procedures in the Pediatric Emergency Department. J Emerg Nurs: JEN : official publication of the Emergency Department Nurses Association. 2019;45(3):278-85. doi: 10.1016/j.jen.2018.07.003.

17. Zhang A, Yocum RM, Repplinger MD, Broman AT, Kim MK. Factors Affecting Family Presence During Fracture Reduction in the Pediatric Emergency Department. Western J Emerg Med. 2018;19(6):970-6. doi: 10.5811/westjem.2018.9.38379.

18. Bashti S, Aghamohammadi M, Heidarzadeh M. The Impact of Family Visits on the Level of Anxiety in Patients with Angina Pectoris Hospitalized in Intensive Care Units. J Health Care. 2016;18(2):161-9.

19. Tomlinson KR, Golden IJ, Mallory JL, Comer L. Family presence during adult resuscitation: a survey of emergency department registered nurses and staff attitudes. Advanced Emergency Nursing Journal. 2010;32(1):46-58. doi: 10.1097/TME.0b013e3181cbe902.

20. Basal A, Ebrahim A, Sai A. Perception of health care providers, patient's families and patients towards family presence during invasive procedures in emergency care units. J Am Sci. 2012;8(11):152-61.

21. Hung MS, Pang SM. Family presence preference when patients are receiving resuscitation in an accident and emergency department. J Adv Nurs. 2011;67(1):56-67. https://doi.org/10.1111/j.3652648.010.05441.x.

22. Mekitarian FFP, Angelo M. Family's presence in the pediatric emergency room: opinion of health's professionals. Revista Paulista de Pediatria. 2015;33(4):460-6.

http://dx.doi.org/10.1016/j.rpped.2015.03.010

23. Najafi Z, Tagharrobi Z, Taghadosi M, Sharifi K, Farrokhian A. The effect of simultaneous aromatherapy and Quran recitation on anxiety level of patients with myocardial infarction. $J$ facult Nurs Mid. 2014;14(1):700-12.

24. Rezvani Amin M, Siratinir M, Ebadi A, Moradian T. Correlation Visual Analogue Scale and McGill pain questionnaire in patients whit chronic low back pain. J Qom Med Sci Univ. 2013;6(1):31-4.

25. Celik N, Khorshid L. The use of ShotBlocker for reducing the pain and anxiety associated with intramuscular injection. Holistic Nurs Pract. 2015;29(5):261-71. doi: https://doi.org/10.1097/HNP.0000000000000105.

26. Tantikul C, Theeranate $C$. Effect of parental presence while children undergo common invasive procedures. J Med Assoc Thai. 2014;97(suppl 2):S153-S8.

27. Ozcetin M, Suren M, Karaaslan E, Colak E, Kaya S, Guner O. Effects of parent's presence on pain tolerance in children during venipuncture: A randomised controlled trial. Hong Kong J Pediatr. 2011;16:247-52.

28. Rafiee Vardanjani L, Safdari Dahcheshmeh F. The effect of the presence of an attendant on anxiety and labor pain of primiparae referring to Hajar Hospital in Shahre Kurd, 2010. J ResDevelop Nurs Mid. 2012;9(1):41-50. 
29. Motarjemizadeh G, Karami N, Mahoori A, Khamseloei F. The Effect of Parental Presence During Induction of Anesthesia On Emergence Agitation After Strabismus Surgery. J Urmia Univ Med Sci. 2017;28(7):447-52.

30. De Stefano C, Normand D, Jabre P, Azoulay E, Kentish-Barnes N, Lapostolle F, et al. Family Presence during Resuscitation: A Qualitative Analysis from a National Multicenter Randomized Clinical Trial. PloS one. 2016;11(6):e0156100. doi: 10.1371/journal.pone.

31. Singh S, Chanu S, Chaudhary A. Effectiveness of Diversional Activity on Pain and Anxiety during Venipuncture among Children in a Selected Hospital Dehradun, Uttarakhand. Pediatr Ther. 2017;7(334):2-8. doi: 10.4172/2161-0665.1000334.

32. Sameei Zadeh T, Mohammadinia N, Sereshti M. Effect of Companionship during Labor on Level of Anxiety of Primiparous Mothers and Midwives Points of View in Iranshahr, 2010. J Mazandaran Univ Med Sci. 2013;22(96):41-8.

33. Salehi A, Fahami F, Beigi M. The effect of presence of trained husbands beside their wives during childbirth on women's anxiety. Iran J Nurs Mid Res. 2016;21(6):611-18.

34. Kherad M, Arab M, Afrasiabi Z, Sadeghi Mehr R. Study the effect family visit on the level of anxiety and sleep quality among burn patients hospitalized in Ghotbodin Shirazi hospital in 2016. J Psychological Mod Method. 2018;8(30):193-204.

35. Koohi M, Bagheri-Nesami M, Esmaeili R, Mousavinasab N, Hosseini H. Effect of family participation in primary care provision to reduce pain anxiety among burn ICU patients. J Mazandaran Univ Med Sci. 2017;26(146):88-99. 